\title{
Study of platelet indices in hyperlipidemia
}

\author{
Ranjana Hawaldar ${ }^{1, *}$, Sadhna Sodani ${ }^{2}$ \\ ${ }^{1}$ Consultant, Dept. of Pathology, Sampurna Sodani Diagnostic Clinic, Indore, Madhya Pradesh, ${ }^{2}$ Associate Professor, Dept. of \\ Microbiology, MGM Medical College, Devi Ahilya University, Indore, Madhya Pradesh, India
}

*Corresponding Author:

Email: drranjana@sampurnadiagnostics.com

\begin{abstract}
Introduction: Atherosclerosis is a chronic inflammatory condition $\mathrm{n}$ resulting from hyperlipidemia and involves platelet mediated recruitment of white blood cells to arteries. The platelet activation is measured indirectly through several platelet indices routinely available without any additional cost in newer fully automated haematology analysers. These indices include platelet count, mean platelet volume(MPV), platelet distribution width(PDW), plateletcrit(PCT), mean platelet(component) concentration (MPC), mean platelet dry mass (MPM), platelet large cell count and platelet large cell ratio (PLCR).. The present study was undertaken in the pathology department of our diagnostic centre to find an association between platelet indices reported by Advia 2120(Siemens) fully automated haematology analyser and hyperlipidemia.

Materials and Methods: This was a prospective study carried out in our diagnostic centre from April to July 2018 . 100 patients with hyperlipidemia without any associated diseases and 100 controls with normal lipid profile were included in the study. Statistical analysis was done using Pearson's correlation test and data was expressed as mean \pm SD for each parameter. A $p$ value of $<0.05$ was considered to be significant.

Results: Maximum number of patients were in 41-60 years of age (65\%). The male to female ratio was 1.7: 1 with $63 \%$ males and $37 \%$ females. The mean cholesterol ,mean triglyceride and mean HDL cholesterol level in study group was $218.6 \pm 36.3$, $244.3 \pm 154,38.7 \pm 9.6$ respectively and $158 \pm 26.8,94.1 \pm 34.8$, and $42.1 \pm 9.3$ in control group respectively. Mean LDL cholesterol was $131.1 \pm 39.4$ in study group and $97.1 \pm 25.2$ in control group. There was a significant difference in platelet counts in both groups with a $p$ value of 0.01 . PCT and MPC also showed a $p$ value of 0.004 . The mean platelet mass (MPM) was $2.17 \pm 0.2$ in study group as compared to $2.13 \pm 021$ in control group. Large platelet count was $7.09 \pm 4.9$ in study group while it was $5.95 \pm 3.81$ in control group which was also significantly different.

Conclusion: Our study indicates that PCT, MPM large platelets and platelet count are significantly higher in hyperlipidemia patients. These indices are available without any additional cost to clinicians, pathologists and patients and can be used to assess the risk associated with hyperlipidemia.
\end{abstract}

Keywords: Hyperlipidemia, MPV, Plateletcrit, MPC, MPM, PLC-R.

\section{Introduction}

The role of hyperlipidemia as a major risk for coronary heart disease, stroke and myocardial infarction has been known since long and several studies have been conducted all over the world linking the role of increased lipids with diabetes, coronary artery disease ,hypertension and obesity. ${ }^{1-5}$ However, hyperlipidemia is mostly diagnosed during a regular health checkup and often goes unnoticed in the absence of any specific symptoms.

Platelets and their role in haemostasis and thrombosis has been studied in great details worldwide but now the focus is on studies correlating the role of platelets in immunity and inflammation in healthy subjects as well as in diseased individuals. ${ }^{6-8}$

Atherosclerosis is a chronic inflammatory condition resulting from hyperlipidemia and involves platelet mediated recruitment of white blood cells to arteries. ${ }^{9-11}$ When the arteries are inflammed due to atherosclerosis, platelets are activated and interact with endothelial cells and deposit platelet derived cytokines on the surface of the endothelial cells, thereby facilitating deposition of leucocytes on the surface of these lesions. ${ }^{12}$ Hypercholesterolemia and hyperlipidemia in general is known to cause platelet activation and thrombotic events. ${ }^{13-15}$ Large platelets are known to be more active metabolically, enzymatically and functionally as compared to smaller platelets. ${ }^{16}$ They are considered to produce more Thromboxane A2 leading to a potentially increased thrombogenic tendency. ${ }^{17,18}$ The platelet activation is measured indirectly through several platelet indices routinely available without any additional cost in newer fully automated haematology analysers. These indices include platelet count, mean platelet volume(MPV), platelet distribution width(PDW), plateletcrit(PCT), mean platelet(component) concentration (MPC), mean platelet dry mass (MPM), platelet large cell count and platelet large cell ratio (PLC-R). Several studies have shown a positive correlation between MPV and hyperlipidemic states, coronary artery disease, cerebral stroke and Diabetes mellitus.

The present study was undertaken in the pathololgy department of our diagnostic centre to find an association between platelet indices reported by Advia 2120(Siemens) fully automated haematology analyser and hyperlipidemia. 


\section{Materials and Methods}

This was a prospective study carried out in our diagnostic centre from April to July 2018. The study included all patients of both sexes above 20 years of age coming to our diagnostic centre for routine health checkup. These patients underwent lipid profile testing after 12-14 hours of overnight fasting and a complete blood count as a part of their routine health checkup. 100 patients with hyperlipidemia without any associated diseases and 100 controls with normal lipid profile were included in the study. We excluded patients with any other associated disease such as known history of coronary heart disease, diabetes mellitus or hypertension or patients receiving medications for any of these conditions as they may affect the lipid levels and platelet indices. Patients with Haemoglobin below $12.0 \mathrm{gm} \%$ in males and $11.0 \mathrm{gm} \%$ in females were also excluded from the study as anaemia is known to cause reactive thrombocytosis and may affect the platelet indices. All patients with cholesterol $\geq 200 \mathrm{mg} \%$, triglycerides $\geq 150 \mathrm{mg} \%$ and HDL cholesterol $\leq 35 \mathrm{mg} \%$ were included in the study group according to the third report of the national cholesterol education programme (NCEP) and expert panel on detection, evaluation and treatment of high blood cholesterol in adults(adult treatment panel III) 2002.

Blood was collected in plain red top tubes for lipid profile and in K2 EDTA for complete blood count by standard protocol and were analysed within one hour of collection to avoid any changes in platelet indices due to prolonged storage which might affect the results. Lipid profile testing was done on Dade Dimension RxL Max (Siemens) and CBC was performed on Advia 2120 (Siemens) 5 part fully automated haematology analyser. In addition to routine CBC parameters Advia 2120 also gives platelet indices which include mean platelet volume(MPV), platelet distribution width(PDW), plateletcrit(PCT), mean platelet(component) concentration (MPC), mean platelet (dry) mass (MPM), platelet large cell count . The platelet large cell ratio (PLC-R) was calculated from the platelet count and large platelet count. Stastical analysis was done using Pearson's correlation test and data was expressed as mean \pm SD for each parameter. A $p$ value of $<0.05$ was considered to be significant.

\section{Results}

A total of 100 patients with hyperlipidemia above 20 years of age were included in the study group with 100 age matched controls with normal lipid profile results. The patients were divided into 21-40, 41-60, 61-80 and > 80 years of age in both the sexes. Maximum number of patients were in 41-60 years of age $(65 \%)$ followed by $26 \%$ in $21-40$ years of age , $8 \%$ in 61-80 years age group and one patient above 80 years of age. The male to female ratio was 1.7: 1 with $63 \%$ males and $37 \%$ females. (Table 1). The mean age was $48.1 \pm 11.9$ in study group and $49.4 \pm 13.7$ in the control group. The mean cholesterol ,mean triglyceride and mean HDL cholesterol level in study group was $218.6 \pm 36.3, \quad 244.3 \pm 154,38.7 \pm 9.6$ respectively and $158 \pm 26.8,94.1 \pm 34.8$, and $42.1 \pm 9.3$ in control group respectively. Mean LDL cholesterol was $131.1 \pm 39.4$ in study group and 97.1 \pm 25.2 in control group(Table 2). There was significant difference in cholesterol, triglyceride and LDL cholesterol levels in both the groups. When platelet parameters were compared in both the groups, it was observed that the mean platelet count was $320 \pm 78.8$ in study group as compared to $306 \pm 76.8$ in control group. There was a significant difference in platelet counts in both groups with a $p$ value of 0.01 . PCT and MPC also showed a $p$ value of 0.004 . The mean platelet mass (MPM) was $2.17 \pm 0.2$ in study group as compared to $2.13 \pm 021$ in control group. Large platelet count was $7.09 \pm 4.9$ in study group while it was $5.95 \pm 3.81$ in control group which was also significantly different. However, the PLC-R did not show a significant difference in both groups. (Table 3).However, PLC-R was above the normal range in both the groups. (Table 4)

Table 1: Demographic data of patients in study group

\begin{tabular}{|l|c|c|c|c|}
\hline \multicolumn{1}{|c|}{ Age } & Male & Female & Total & \% \\
\hline $21-40$ & 21 & 5 & 26 & $26.0 \%$ \\
\hline $41-60$ & 36 & 29 & 65 & $65.0 \%$ \\
\hline $61-80$ & 5 & 3 & 8 & $8.0 \%$ \\
\hline$>80$ & 1 & 0 & 1 & $1.00 \%$ \\
\hline Total & 63 & 37 & 100 & \\
\hline
\end{tabular}

Table 2: Comparison of Patients in study and control groups

\begin{tabular}{|l|c|c|l|l|l|}
\hline Parameter & Total & Study group & $\begin{array}{l}\text { Normal } \\
\text { Controls }\end{array}$ & R Value & P value \\
\hline & & Mean \pm SD & Mean \pm SD & & \\
\hline $\begin{array}{l}\text { Total cases } \\
\text { (Male+Female) }\end{array}$ & 200 & & & & \\
\hline Male(\%) & $60.0 \%$ & & & & \\
\hline Female (\%) & $40.0 \%$ & & & & \\
\hline Age (in years) & 200 & $48.1 \pm 11.9$ & $49.4 \pm 13.7$ & & \\
\hline Cholesterol & 200 & $218.6 \pm 36.3$ & $158 \pm 26.8$ & 0.0187 & 0.79 \\
\hline
\end{tabular}




\begin{tabular}{|l|c|c|c|c|c|}
\hline Triglycerides & 200 & $244.3 \pm 154$ & $94.1 \pm 34.8$ & 0.1892 & 0.01 \\
\hline HDL & 200 & $38.7 \pm 9.6$ & $42.1 \pm 9.3$ & 0.013 & 0.86 \\
\hline LDL & 200 & $131.1 \pm 39.4$ & $97.1 \pm 25.2$ & 0.1359 & 0.06 \\
\hline
\end{tabular}

Table 3: Comparison of Platelets Parameters in study and control groups

\begin{tabular}{|l|c|c|c|c|c|}
\hline Parameter & Total & Study group & Normal Controls & R Value & P value \\
\hline & & Mean \pm SD & Mean \pm SD & & \\
\hline Platelets & 200 & $320.6 \pm 78.8$ & $306 \pm 76.8$ & 0.1962 & 0.01 \\
\hline MPV & 200 & $8.5 \pm 1.2$ & $8.4 \pm 0.76$ & -0.0265 & 0.71 \\
\hline PDW & 200 & $49.7 \pm 8.3$ & $49.4 \pm 8.3$ & -0.0778 & 0.28 \\
\hline PCT & 200 & $0.28 \pm 0.1$ & $0.26 \pm .07$ & 0.2476 & 0.0004 \\
\hline MPC & 200 & $26.9 \pm 1.7$ & $26.2 \pm 3.01$ & -0.2467 & 0.0004 \\
\hline MPM & 200 & $2.17 \pm 0.2$ & $2.13 \pm 0.21$ & -0.0203 & 0.78 \\
\hline $\begin{array}{l}\text { Large } \\
\text { Platelet }\end{array}$ & 200 & $7.09 \pm 4.9$ & $5.95 \pm 3.81$ & 0.0159 & 0.82 \\
\hline PLCR & 200 & $72.9 \pm 59.9$ & $74.82 \pm 67.5$ & 0.0358 & 0.61 \\
\hline
\end{tabular}

Table 4: Normal Range for Platelet Parameters

\begin{tabular}{|l|c|c|}
\hline \multicolumn{1}{|c|}{ Parameter } & Range & Units \\
\hline Platelets & $140-360$ & $\mathrm{x} 10^{3} / \mathrm{uL}$ \\
\hline Mean Platelet Volume (MPV) & $7.0-9.0$ & $\mathrm{fl}$ \\
\hline Platelet Distribution Width (PDW) & $41.9-65.1$ & $\%$ \\
\hline Plateletcrit (PCT) & $0.108-0.282$ & $\%$ \\
\hline Mean Platelet (Component) Concentration (MPC) & $26.4-28.8$ & $\mathrm{~g} / \mathrm{dL}$ \\
\hline Mean Platelet (dry) Mass (MPM) & $1.76-2.52$ & $\mathrm{pg}$ \\
\hline Platelet Large Cell Ratio (PLC-R) & $11.0-45.0$ & \\
\hline
\end{tabular}

Table 5: Normal Range for Lipid Parameters

\begin{tabular}{|l|l|c|}
\hline Parameter & Range & Units \\
\hline Cholesterol & $\begin{array}{l}\text { Desirable: <200 Borderline: 200 - 239 High Risk: } \\
240\end{array}$ & $\mathrm{mg} / \mathrm{dL}$ \\
\hline HDL Cholesterol & Desirable: 60 Borderline: 35 - 45 High Risk: <35 & $\mathrm{mg} / \mathrm{dL}$ \\
\hline Triglycerides & $\begin{array}{l}\text { Desirable: <150 Borderline: 150 - 199 High Risk: } \\
200-499\end{array}$ & $\mathrm{mg} / \mathrm{dL}$ \\
\hline LDL Cholesterol & $\begin{array}{l}\text { Desirable: } 60-130 \text { Borderline: } 130-159 \text { High } \\
\text { Risk: } 160-189\end{array}$ & $\mathrm{mg} / \mathrm{dL}$ \\
\hline
\end{tabular}

\section{Discussion}

Coronary artery disease is one of the major causes of morbidity and mortality in the world as well as in the Indian population. Atherosclerosis is a major causative pathological factor for CHD and usually starts in the second decade of life due to hyperlipidemia and by the fourth decade of life manifests as CHD. Platelets are known to convert chronic atherosclerotic plaques into a thrombus causing occlusion of the arteries. ${ }^{19}$ The platelet count is a parameter which reflects the functioning, production and ageing of the platelets. ${ }^{20}$ MPV is used to assess the size and function of the platelets. PDW, on the other hand, is an indicator of the size distribution of the platelets and an increased PDW is considered to be an indicator of increased thrombotic tendency in individuals. ${ }^{21}$ Large platelets have a high metabolic activity and contain more dense granules and are thus have a potential to cause platelet aggregation as compared to smaller platelets. ${ }^{21,22}$ MPC or the mean platelet component concentration, a parameter reported by Advia 2120, when reduced, indicates platelet activation, reflecting a decrease in platelet density.

In our study, we found a male to female ratio of 1.7:1 which correlates with the study of Khemka $\mathrm{R}$ et al. In their study, maximum patients were in 51-70 years age group. ${ }^{23}$ In their study, they found a significant difference between MPV, PDW and PLC-R in study and control group. However, in our study, we found a significant difference in platelet counts, PCT, MPC and large platelet count in study and control groups while no significant difference was observed in MPV, PDW and PLC-R. In a study by Grotto et al, MPV, PDW and PLC-R were significantly higher in the hyperlipidemia patients as compared to normal controls. ${ }^{24}$ Chih Hao Tseng et al in their study observed a significant difference in MPV, PDW and PLC-R between study and control groups and a positive correlation with LDL/HDL ratio. ${ }^{25}$ Our study correlates 
with the study of Dogru et al who did not find a significant correlation between MPV and hyperlipidemia. ${ }^{26}$ The study by Ravindran et al did not show any significant correlation between platelet count and hypercholesterolemia. ${ }^{27}$

The difference in the observation between different studies may be due to the fact that we included the patients without any associated clinical disease while others may have included patients with associated CHD, Diabetes and hypertension with hyperlipidemia which may have affected the platelet indices. The novel platelet parameters like MPM, MPC and PCT reported by Advia 2120 have not been studied so far in published studies and probably this is the first study to find an association between hyperlipidemia and these novel parameters. We found a significant correlation between MPC and PCT in our study.

It is suggested that hypercholesterolemia leads to priming of platelets and increases the platelet activity by increasing platelet production. As the platelets are activated, the risk of CAD increases. The accumulation of cholesterol particles in platelets or defective cholesterol efflux pathways leads to increased platelet production and increased activity of platelets thereby causing atherosclerosis and increased possibility of a thrombotic event.

In a study by Khandekar et al it was observed that all platelet indices are significantly raised in patients with acute MI as compared to those with stable CAD. ${ }^{28}$ Damodar et al observed that raised MPV is not a risk factor for development of acute coronary syndrome. ${ }^{29}$

Our study has few limitations. The sample size is small which may have created a potential bias in the observations. Additional multicentric studies involving large population groups and all ethnic groups would be required to confirm and validate the role of different platelet indices in the pathogenesis of hyperlipidemia and subsequent atherosclerosis.

\section{Conclusion}

Hyperlipidemia may cause a variety of thromboembolic complications and platelet indices reported by modern day automated haematology analysers are used to assess the risk of such events in hyperlipidemic patients. Our study indicates that PCT, MPM, large platelets and platelet count are significantly higher in hyperlipidemia patients. These indices are available without any additional cost to clinicians, pathologists and patients and can be used to assess the risk associated with hyperlipidemia.

Funding: No funding sources.

Conflict of interest: None declared.

\section{References}

1. Ross R. The pathogenesis of atherosclerosis: an update. N Engl J Med 1986;314:488-500.
2. Lacoste L, Lam JY, Hung J, Letchacovski G, Solymoss CB, Waters D. Hyper- lipidemia and coronary disease. Correction of the increased thrombogenic potential with cholesterol reduction. Circulation 1995;92:3172-7.

3. Saluja JG, Ajinkya MS, Khemani B. Com- parative study of serum lipids and fibrino- gen levels in diabetes mellitus and its clin- ical significance in Indian population. Bombay Hospital J 2000;42:466-70.

4. Castelli WP, Anderson K. A population at risk: prevalence of high cholesterol levels in hypertensive patients in the Framingham study. Am J Med 1986;80(2 suppl1):23-32

5. Ames RP. Hyperlipidemia in hypertension:causes and prevention. Am Heart J 1991;122:1219-24.

6. Semple JW, Italiano JE, Jr, Freedman J. Platelets and the immune continuum. Nat Rev Immunol 2011;11(4):26474.

7. Davì G, Patrono C. Platelet activation and atherothrombosis. N Engl J Med 2007;357(24):2482-94.

8. Engelmann B, Massberg S. Thrombosis as an intravascular effector of innate immunity. Nat Rev Immunol 2013;13(1):34-45.

9. Ross R. Atherosclerosis--an inflammatory disease. $N$ Engl J Med 1999;340(2):115-26.

10. Libby P, Ridker PM, Hansson GK. Progress and challenges in translating the biology of atherosclerosis. Nature 2011;473(7347):317-325.

11. Huo Y, Schober A, Forlow SB, et al. Circulating activated platelets exacerbate atherosclerosis in mice deficient in apolipoprotein E. Nat Med 2003;9(1):61-67.

12. Koenen RR, von Hundelshausen P, Nesmelova IV, et al. Disrupting functional interactions between platelet chemokines inhibits atherosclerosis in hyperlipidemic mice. Nat Med 2009;15(1):97-103

13. Carvalho AC, Colman RW, Lees RS. Platelet function in hyperlipoproteinemia. N Engl J Med 1974;290(8):43438.

14. Connor WE, Hoak JC, Warner ED. Massive thrombosis produced by fatty acid infusion. $J$ Clin Invest 1963;42(6):860-66.

15. Owens AP, III, Passam FH, Antoniak S, et al. Monocyte tissue factor-dependent activation of coagulation in hypercholesterolemic mice and monkeys is inhibited by simvastatin. J Clin Invest 2012;122(2):558-68.

16. Corash L, Tan H, Gralnick HR. Heteroge- neity of human whole blood platelet sub- populations. I. Relationship between buoyant density, cell volume and ultra- structure. Blood 1977;49:71-87.

17. Martin JF, Trowbridge EA, Salmon G, Plumb J. The biological significance of platelet volume: its relationship to bleeding time, platelet thromboxane $\mathrm{B} 2$ production and megakaryocyte nuclear DNA concen- tration. Thromb Res 1983;32:443-60.

18. Khandekar MM, Khurana AS, Deshmukh SD, Kakrani $\mathrm{AL}$, Katdare AD, Inamdar AK. Platelet volume indices in patients with coronary artery disease and acute myocardial infarction: an Indian scenario. $J$ Clin Pathol 2006;59:146-49.

19. Trip MD, Cats VK, van Capelle FJL, et al. Platelet hyperreactivity and prognosis in survivors of myocardial infarction. New Engl J Med 1990;322:1549-54.

20. Du J, Wang Q, He B, Liu P, Chen JY, Quan H, Ma X. Association of mean platelet volume and platelet count with the development and prognosis of ischemic and hemorrhagic stroke. Int J Lab Hematol 2016;38:233-39.

21. Yilmaz F, Koklu E, Kizilirmak Yilmaz F, Sarionder Gencer E, Alparslan AS, Yildirimturk O. Evaluation of mean platelet volume and platelet distribution width in 
patients with asymptomatic intermediate carotid artery plaque. Kardiol Pol 2017;75:35-41.

22. Tasdemir S, Erdem HB, Sahin I, Ozel L, Ozdemir G, Eroz R, Tatar A. Correlation with Platelet Parameters and Genetic Markers of Thrombophilia Panel (Factor II g.20210G >A, Factor V Leiden, MTHFR (C677T, A1298C), PAI-1, beta-Fibrinogen, Factor XIIIA (V34L), Glycoprotein IIIa (L33P)) in Ischemic Strokes. Neuromolecular Med 2016;18:170-76.

23. Khemka R, Kulkarni K. Study of relationship between Platelet Volume Indices and Hyperlipidemia. Ann Pathol Laboratory Med 2014;1(1):8-14

24. Grotto HZ, Noronha JF. Platelet large cell ratio (P-LCR) in patients with dyslipidemia. Clin Lab Haematol 2004;26:347-9

25. Chih-Hao Tseng, Yu-Jen Chang, Tung-Hua Chiang, YaLing Liao Evaluation of Platelet Volume Indices in Adults with Hyperlipidemia and Correlation with Lipid Ratio. Cheng Ching Medical J 2016;12(4):10-15.
26. Dogru T, Tasci I, Naharci MI, Sonmez A, Erdem G, Kilic $\mathrm{S}$, et al. Mean platelet volume levels in metabolic syndrome. AJCI 2007;1:99-105.

27. Ravindran R, Krishnan LK. Incresased platelet cholesterol and decreased per- centagre volume of platelets as a secondary risk factor for coronary artery disease. Pathophysiol Haemost Thromb 2007;36:45-51.

28. Khandekar MM, Khurana AS, Deshmukh SD, Kakrani $\mathrm{AL}$, Katdare AD, Inamdar AK. Platelet volume indices in patients with coronary arterydisease and acute myocardial infarction: an Indianscenario. J Clin Pathol 2006;59:14649.

29. Damodar S, Ganesh KV, Murthy S. Mean Platelet Volume does not predict risk of myocardial infarction or coronary artery disease in Indian patients. Platelets 2008;19(1):80-1.

How to cite this article: Hawaldar R., Sodani S. Study of platelet indices in hyperlipidemia. J Diagn Pathol Oncol 2018;3(4):299-303. 